\title{
Protecting the underscreened women in developed countries: the value of HPV test
}

Raquel Ibáñez ${ }^{1}$, Josefina Autonell ${ }^{2}$, Montserrat Sardà2 ${ }^{2}$ Nayade Crespo ${ }^{3}$, Pilar Pique ${ }^{3}$, Amparo Pascual $^{3}$, Clara Martí $^{4}$, Montserrat Fibla ${ }^{5}$, Cristina Gutiérrez ${ }^{6}$, Belén Lloveras ${ }^{7}$, Judit Moreno-Crespi ${ }^{8}$, Anna Torrent ${ }^{9}$, Núria Baixeras ${ }^{10}$, María Alejo ${ }^{11}$, Francesc Xavier Bosch ${ }^{1}$ and Silvia de Sanjosé 1,12* $^{*}$

\begin{abstract}
Background: Poor attendance to cervical cancer (CC) screening is a major risk factor for CC. Efforts to capture underscreened women are considerable and once women agree to participate, the provision of longitudinal validity of the screening test is of paramount relevance. We evaluate the addition of high risk HPV test (HPV) to cervical cytology as a primary screening test among underscreened women in the longitudinal prediction of intraepithelial lesions grade 2 or worse (CIN2+).
\end{abstract}

Methods: Women were included in the study if they were older than 39 years and with no evidence of cervical cytology in the previous five years within the Public Primary Health Care System in Catalonia (Spain). 1,832 underscreened women from eight public primary health areas were identified during 2007-2008 and followed-up for over three years to estimate longitudinal detection of CIN2+. Accuracy of each screening test and the combination of both to detect CIN2+ was estimated. The risk of developing CIN2+ lesions according to histology data by cytology and HPV test results at baseline was estimated using the Kaplan-Meier method.

Results: At baseline, $6.7 \%$ of participants were HPV positive, $2.2 \%$ had an abnormal cytology and $1.3 \%$ had both tests positive. At the end of follow-up, 18 out of 767 (2.3\%) underscreened women had a CIN2+, two of which were invasive CC. The three-year longitudinal sensitivity and specificity estimates to detect CIN2+ were 90.5\% and 93.0\% for HPV test and $38.2 \%$ and $97.8 \%$ for cytology. The negative predictive value was $>99.0 \%$ for each test. No additional gains in validity parameters of HPV test were observed when adding cytology as co-test. The referral to colposcopy was higher for HPV but generated 53\% higher detection of CIN2+ compared to cytology.

Conclusions: Underscreened women had high burden of cervical disease. Primary HPV screening followed by cytology triage could be the optimal strategy to identify CIN2+ leading to longer and safe screen intervals.

Keywords: Human papilloma virus, Cervical cytology, Pap smear, Cervical cancer screening, HC2 testing, HPV test, Sensitivity, Specificity, Underscreened women

\section{Background}

Infection with high-risk human papillomavirus types (HPV) is the necessary cause for the development of cervical cancer (CC) [1]. Historically, organized screening using cytology at regular intervals with a high coverage has reduced the incidence of invasive CC in many countries $[2,3]$. Absence or poor screening history remains the

\footnotetext{
* Correspondence: raquelip@iconcologia.net

'Unit of Infections and Cancer; Cancer Epidemiology Research Programme, IDIBELL, Catalan Institute of Oncology (ICO), 08908 L'Hospitalet de Llobregat, Barcelona, Spain

${ }^{12}$ CIBER Epidemiology and Public Health, Barcelona, Spain

Full list of author information is available at the end of the article
}

major risk factor for $\mathrm{CC}$, and can contribute to over half of CC cases [4-9].

Primary CC screening with HPV detection has been shown in randomized controlled trials (RCTs) to have higher longitudinal sensitivity to detect cervical intraepithelial neoplasia grade 2 or worse (CIN2+) than conventional cytology, maintaining a high negative predictive value (NPV) [10-14].

In the Autonomic region of Catalonia (Spain), routine screening with cervical cytology is recommended to women aged 25-65 with a 3-year interval. Although screening is opportunistic, within the Public Health System 
efforts to increase $\mathrm{CC}$ screening coverage in underscreened women have been established [15]. These activities are facilitated by raising awareness and a campaign was launched amongst midwives, gynaecologists and family practitioners to identify poorly screened women when visiting Primary Health Care services. Women identified as being underscreened were offered a screening visit that included co-testing with HPV testing and cervical cytology in order to assure the highest accuracy of the visit. The rationale was based on the very high sensitivity and high NPV of joint testing for an extended period of three years [10-14].

The aim of this study was to evaluate the addition of HPV test to cervical cytology as a primary screening test among the underscreened population in the longitudinal prediction of CIN2+.

\section{Methods}

1,832 women older than 39 years old were included. Women were selected if they had no evidence of cervical cytology in the public primary health registries in the previous five years. Women identified in eight public primary health areas of Catalonia during 2007 and 2008 were included in this study and followed-up until June 2012 (Figure 1). These women categorized as being underscreened for $\mathrm{CC}$ were offered cytology and HPV test at recruitment. If both tests were negative, followup was recommended every 3 years until age 65 . Women were referred to colposcopy if either test was positive. Women older than 65 years old and with both negative tests exited the screening activity [15].
The pathology laboratories (Hospital Universitari Dr. Josep Trueta, Consorci hospitalari de Vic, Hospital Universitari Joan XXIII, Hospital del Mar, Hospital Universitari de Bellvitge, Hospital General de Granollers, Hospital d'Althaia and Laboratori d'Atenció Primària Dr. Robert) provided information on age, results and date of cytologies, histologies and HPV tests during the study period for each woman. The overall project was approved by the ethical committee of the Catalan Institute of Oncology. Any information regarding the identification of patients was anonymized before analysis.

\section{Screening tests}

HPV detection was performed with the FDA-approved Hybrid Capture 2 test (HC2; Qiagen, Gaithersburg, MD, USA) which detects 13 high-risk HPV types $(16,18,31,33,35,39,45,51,52,56,58,59$ and 68). An HPV sample was considered positive if attained or exceeded the FDA-approved threshold of $1.0 \mathrm{pg} \mathrm{HPV} \mathrm{DNA} \mathrm{ml}{ }^{-1}$, which corresponds to 1.0 relative light unit (RLU/CO). All HPV reference laboratories participated in an interlaboratory quality control with kappa values over 90\% [16].

Cytologies were performed largely with conventional Pap smears. Few centres used liquid based cervical cytology and in such cases the HPV and the cytology was performed in the same sample. All the cytological results were classified according to the 2001 Bethesda system [17]. Abnormal or positive cytology was defined as atypical squamous cell of undetermined significance (ASC-US) or more severe cytological diagnosis.

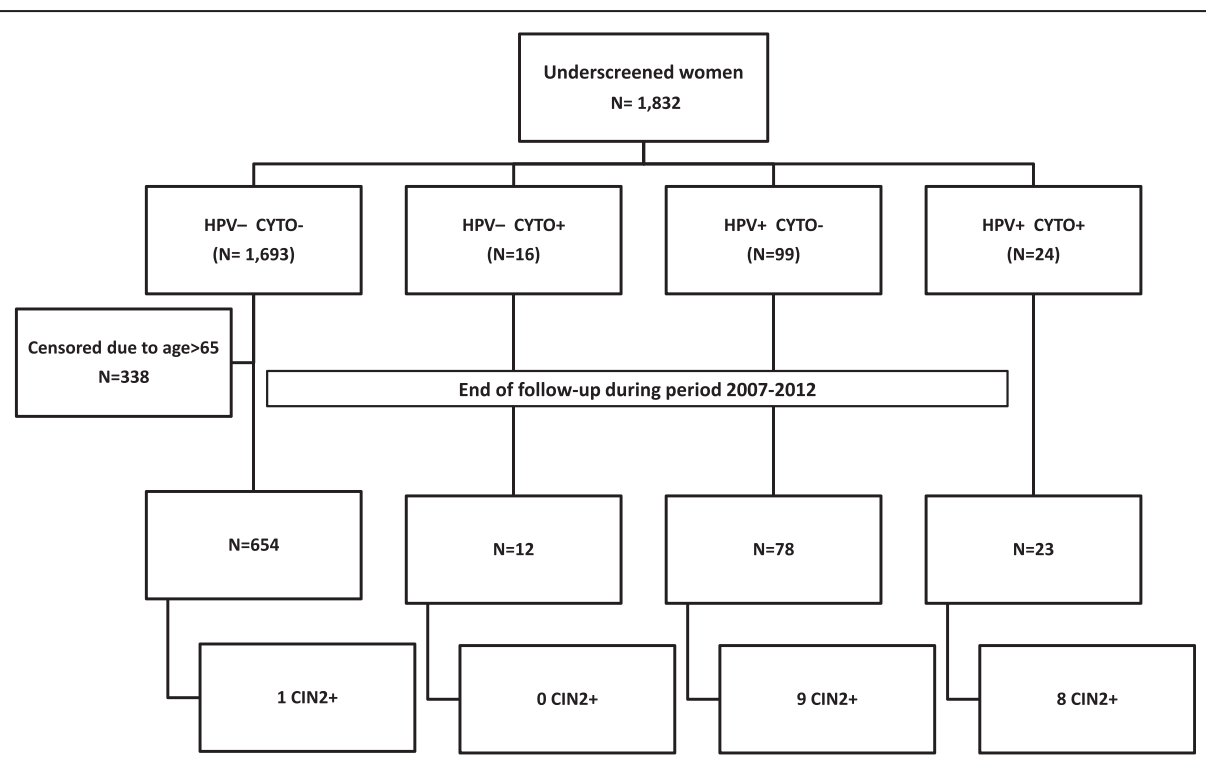

Figure 1 Flowchart for the selection of the study population. Underscreened women are defined as women older than 39 years and with no records on cervical cytology during the previous five years. CIN2+: cervical intraepithelial neoplasia grade 2 or worse. 
The CIN classification was used to categorize histological results [18].

\section{Follow-up}

The end-point of follow-up was established at the moment of the most severe diagnosis or June 2012. For women with a positive test during the study period, a final diagnosis of "normal" was assigned if at least two negative tests were registered in subsequent visits. For women with both tests negative at baseline a subsequent negative test was requested to be categorised as being negative for CIN2+.

When concomitant cytological and histological results were available, the highest histological grade of abnormality was used for the final diagnosis. Women not having any additional test to those obtained at baseline were considered as lost to follow-up.

\section{Statistical analysis}

Whenever appropriate, estimates are presented by different combinations of screening tests results. Three year longitudinal sensitivity, specificity, positive predictive value (PPV) and NPV for CIN2+ detection and their 95\% CI were calculated for cytology, HPV test and the combination of both. Estimates were corrected taking into account the proportion of women who returned to the next screening round in each screening strata of results as reported elsewhere [19]. We estimated the risk of developing CIN2+ lesions according to histology data by cytology and HPV test result at baseline using the Kaplan-Meier method.

\section{Results}

At baseline, the average age among the 1,832 included women was 54.1 years (range $40-88$ years). Most of them $(92.4 \%)$ had both tests negative. 338 women were relieved from further screening because of being 65 years old or older and had both tests negatives, leaving 1,494 undescreened women to be followed-up. Of them, 767 women (51.3\%) completed follow-up. Lost to follow-up was higher in women with both tests negative when compared to those with at least one positive test $(\mathrm{p}<0.05)$ (Figure 1). Increasing age was significantly associated with decreasing attendance to next screening visit (data not shown).

Positive cytology was registered in $2.2 \%$ and HPV positivity in $6.7 \%$ of the women while $1.3 \%$ had both test positive. Among HPV positive women, 19.5\% had an abnormal cytology. Table 1 summarizes baseline and end of study diagnosis. At the end of follow-up nine CIN2, seven CIN3 and two invasive CC were diagnosed (18/ $767,2.3 \%$ ) and histologically confirmed. All but one CIN2+ were diagnosed among HPV positive women. The two CC detected corresponded to one squamous cell carcinoma (stage II) and one adenocarcinoma (stage I) and had as a baseline cytology diagnosis of ASC-US and of atypical glandular cells of undetermined significance respectively. Nine out of CIN2/3 identified during follow-up had a normal cytology at entry. The mean time between the first positive HPV test and the diagnosis of CIN2+ was 11.7 months. Among women HPV negative at enrolment $96.2 \%$ persisted as negative.

At the end of follow-up, 27 women were classified as having non-HPV related diseases including three endometrial carcinoma cases, five leiomyomatosis and two uterine prolapses within the HPV negative strata. Among the HPV positive, 15 women had a persistent HPV infection with no further cytology data and one had a diagnosis of uterine prolapse.

At 36 months, the cumulative detection of CIN2+ in women with normal cytology and HPV positive at baseline was $14.5 \%$ and $39.3 \%$ in women with both tests being positive (Figure 2).

The longitudinal sensitivity of the HPV test was considerably higher than that of cytology and equal to the combination of both tests for histologically confirmed CIN2+ (90.5; CI 95\%=88.8-92.2) (Table 2). Specificity and PPV were both higher for cytology than HPV alone or co-testing. NPV was high for both tests.

\section{Discussion}

CC screening activities aim to reach asymptomatic women in specific target ages on regular basis. The organization of these activities and the quality control measures are crucial to optimize the resources for the best health benefits. Irrespective of the type of the screening offered, poor attendance by some and over use of the system by others are persistent issues that need to be addressed. Our principal aim was to identify among poorly screened women in a single screening visit any possible cervical intraepithelial lesion that could lead to cancer. To provide the best optimal detection at the time of the visit, HPV was offered as an ancillary test to the cytology to increase longitudinal sensitivity with a minimal impact in specificity. This intervention differed from that given to the regular users of screening facilities in which only cytology was offered every three years or two consecutive cytologies within one year if it was the first screening visit [15].

Co-testing with HPV referred $7.6 \%$ of underscreened women for an either closer follow-up or to immediate colposcopy. If we had used previous guidelines, in which cytology was the screening test, all the women with a first normal cytology at baseline $(97.8 \%)$ had to be screened again within a year in order to correct for poor cytology sensitivity. This was not implemented in our population because of the co-testing recommendation.

Positive cytology was detected in $2.2 \%$ of the women, percentage that was overall similar to that observed in 
Table 1 Diagnosis at follow-up among underscreened women by HPV status and concomitant cytology at baseline

\begin{tabular}{|c|c|c|c|c|c|c|c|c|c|c|}
\hline \multirow[b]{2}{*}{ NEGATIVE HPV TEST AT BASELINE } & & \multirow[b]{2}{*}{$\begin{array}{l}\text { TOTAL } \\
\text { SAMPLE } \\
\text { N (\%) }\end{array}$} & \multirow[b]{2}{*}{$\begin{array}{l}\text { TOTAL FOLLOW } \\
\text { UP SAMPLE } \\
\text { N (\%) }\end{array}$} & \multicolumn{7}{|c|}{ DIAGNOSIS AT LAST FOLLOW UP } \\
\hline & & & & $\begin{array}{l}\text { NORMAL } \\
\text { N (\%) }\end{array}$ & $\begin{array}{l}\text { ASC-US/ASC-H } \\
\text { N (\%) }\end{array}$ & $\begin{array}{l}\text { CIN1 }{ }^{\mathrm{a}} \\
\mathrm{N}(\%)\end{array}$ & $\mathrm{CIN}^{\mathrm{a}}$ & $\begin{array}{l}\mathrm{CIN3}^{\mathrm{a}} \\
\mathrm{N}(\%)\end{array}$ & $\begin{array}{l}\text { CERVICAL } \\
\text { CARCINOMA } \\
\text { N (\%) }\end{array}$ & $\begin{array}{l}\text { OTHERS } \\
\text { RESULTS }^{c} \\
\text { N (\%) }\end{array}$ \\
\hline \multirow{4}{*}{$\begin{array}{l}\text { CONCOMITANT CYTOLOGY RESULT } \\
\text { AT BASELINE }\end{array}$} & Normal & $1693(99.1)^{d}$ & $654(98.2)$ & $641(98.3)^{e}$ & $1(100)$ & $1(100)$ & $1(100)^{f}$ & & & $10(90.9)$ \\
\hline & ASC-US/ASC H/AGC/LSIL & $15(0.8)$ & $11(1.7)$ & $10(1.5)$ & & & & & & $1(9.1)$ \\
\hline & Suspected adenocarcinoma ${ }^{g}$ & $1(0.1)$ & $1(0.2)$ & $1(0.2)$ & & & & & & \\
\hline & TOTAL & $1709(100)$ & $666(100)$ & $652(100)$ & $1(100)$ & $1(100)$ & $1(100)$ & & & $11(100)$ \\
\hline POSITIVE HPV TEST AT BASELINE & & $\begin{array}{l}\text { TOTAL } \\
\text { SAMPLE } \\
\mathrm{N}(\%)\end{array}$ & $\begin{array}{l}\text { TOTAL FOLLOW } \\
\text { UP SAMPLE } \\
\text { N (\%) }\end{array}$ & & & & & & & \\
\hline \multirow{4}{*}{$\begin{array}{l}\text { CONCOMITANT CYTOLOGY RESULT } \\
\text { AT BASELINE }\end{array}$} & Normal & $99(80.5)^{d}$ & $78(77.2)$ & $45(83.3)$ & $6(100)$ & $2(25.0)$ & $6(75)$ & $3(42.9)$ & & $16(100)$ \\
\hline & ASC-US/AGC/LSIL & $19(15.4)$ & $18(17.8)$ & $9(16.7)$ & & $5(62.5)$ & $1(12.5)$ & $1(14.3)$ & $2(100)$ & \\
\hline & HSIL & $5(4.1)$ & $5(5.0)$ & & & $1(12.5)$ & $1(12.5)$ & $3(42.9)$ & & \\
\hline & TOTAL & $123(100)$ & $101(100)$ & $54(100)$ & $6(100)$ & $8(100)$ & $8(100)$ & $7(100)$ & $2(100)$ & $16(100)$ \\
\hline
\end{tabular}

${ }^{\mathrm{a} A l l}$ the CIN1, CIN2, CIN3 and cervical cancer cases was histologically confirmed.

${ }^{\mathrm{b}}$ One of the cases was an infiltrating squamous carcinoma (stage II) diagnosed at 23 months after cytology and HPV testing at baseline. The other case was an adenocarcinoma (stage I) diagnosed one month after study entry.

'Among negative HPV women, there were 3 cases of endometrial carcinoma who underwent a hysterectomy, 7 hysterectomies ( 5 for leiomyomatosis and 2 for prolapse) and one case with second positive HPV test. Among positive HPV women, there were a case with a hysterectomy for prolapse and 15 women with a persistent HPV infection.

dThere were included in this group 23 women whose concomitant cytology at baseline had unsatisfactory results but during the follow up period, all subsequent tests were negative. There was one case in HPV positive arm.

positive arm.
eTwo cases with normal concomitant and negative HPV test at baseline developed endometrial carcinoma during the follow-up period, but follow-up cytologies were normal. Another case with normal concomitant cytology and negative HPV test developed a VIN3 although Pap smears performed during the follow-up period were normal

cytology and negative HPV test developed a VIN3 although Pap smears performed during the follow-up period were normal
fCIN2 was developed after 54 months of cytology and HPV testing at baseline. Conisation was performed but no further data was available.

${ }^{9}$ Finally the suspected of adenocarcinoma was a endometrial carcinoma, but follow-up cytologies were normal.

ASC-US: Atypical squamous cell of undetermined significance, ASC-H: Atypical squamous cells cannot exclude a high grade squamous intraepithelial lesion, AGC: Atypical glandular cells of undetermined significance, ASC-US: Atypical squamous cell of undetermined significance, ASC-H: Atypical squamous cells cannot exclude a high grade squamous intraepithelial lesion, AGC: Atypical glandular cells of undetermined significance,
HPV+: positive for Human Papillomavirus test, CIN-NOS: CIN not otherwise specified, CIN1: high grade cervical intraepithelial lesions grade 1, LSIL: low grade squamous intraepithelial lesion, CIN1: high grade cervical intraepithelial lesions grade 1, CIN2: high grade cervical intraepithelial lesions grade 2, CIN3: high grade cervical intraepithelial lesions grade 3, HSIL: High grade squamous intraepithelial lesion. 


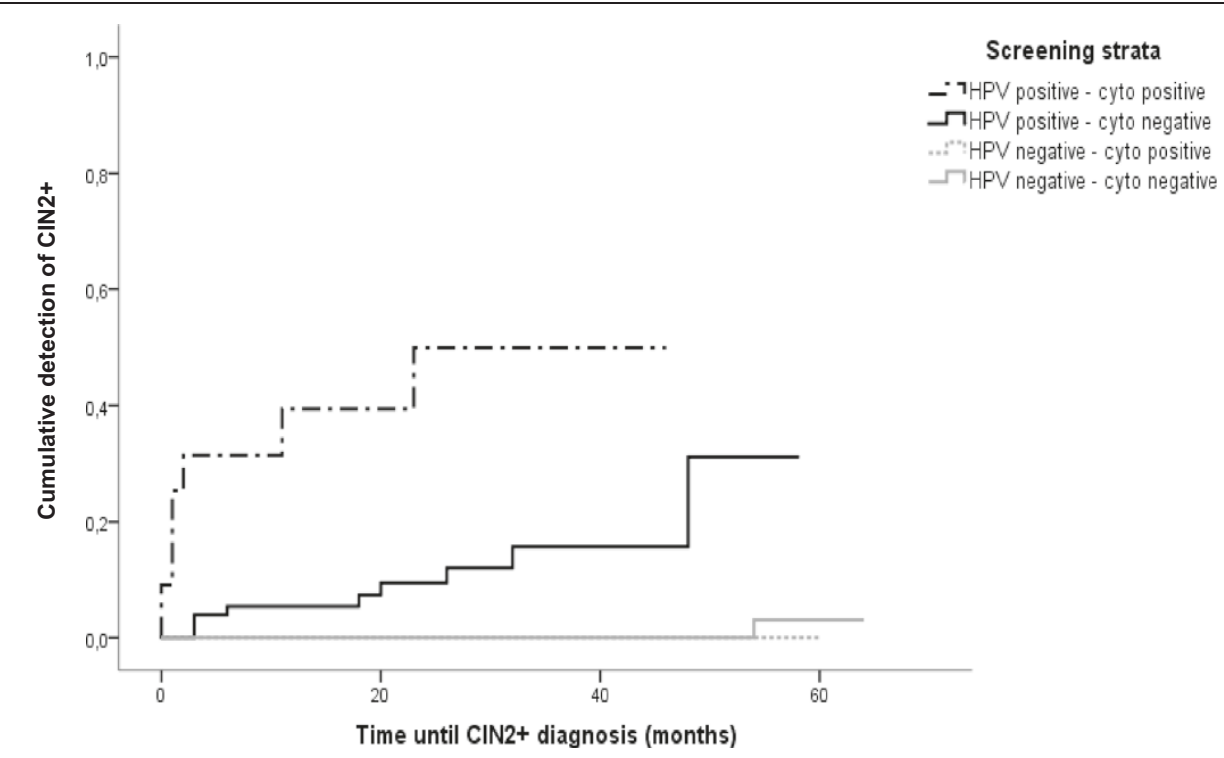

Figure 2 Cumulative detection of CIN2+ according to baseline result of cytology and HPV testing. Detection of CIN2+ in underscreened women based on 767 women. Women were classified into 4 groups depending on the HPV and cytology results at baseline. Note that there is a higher risk of development CIN2+ in positive HPV women with normal cytology.

the general population of the same age group (2.1\%), although lesions in our study were more severe than expected [20]. However, by using HPV test, $6.7 \%$ of the women were positive but we identified over $50 \%$ more $\mathrm{CIN} 2+$ in the three years following the index screening visit than with the solely use of cytology. The difference in cumulative risk of $\mathrm{CIN} 2+$ for those with a double negative tests results compared to those with a HPVnegative test was minimal $(0.2 \%)$ supporting the fact that, in this population, single testing with HPV could be sufficient as the first screening test. These results were consistent with the state of the art knowledge provided by several RCTs comparing clinically validated HPV tests with cytology as primary screening tests [10-12,14,21]. Further, meta-analysis of studies using HC2 as HPV test, reached an overall longitudinal sensitivity of $96.3 \%$ and a specificity of $91.4 \%$ for CIN2+ detection, the latter being slightly lower than the one observed for cytology [13]. In our data we observed a loss of $4.8 \%$ in longitudinal specificity when using HPV test alone compared to cytology alone. To avoid this drop in specificity appropriate algorithms must be implemented as triage tests such as reflex cytology or HPV genotyping for HPV16 or 18 and others $[12,13,22,23]$.

The cumulative detection of CIN2+ among women with normal cytology at baseline was high for HPV positive women at baseline compared to those HPV negative and comparable to that seen in other screening cohorts $[12,24]$. Our findings suggest that the main benefit of HPV testing is the identification of women harbouring

Table 2 Accuracy of HPV test, cytology and the combination of both tests for CIN2+ prediction

\begin{tabular}{lcccc}
\hline & & HPV & CYTOLOGY & HPV + CYTOLOGY \\
\hline \multirow{2}{*}{ SENSITIVITY (95\% Cl) } & Uncorrected $^{a}$ & $94.4(92.8-96.1)$ & $44.4(39.2-49.7)$ & $94.4(92.8-96.1)$ \\
& Corrected $^{b}$ & $90.5(88.8-92.2)$ & $38.2(33.9-42.6)$ & $90.5(88.8-92.2)$ \\
SPECIFICITY (95\% Cl) & Uncorrected $^{a}$ & $88.8(86.4-91.2)$ & $96.4(95.1-97.7)$ & $87.2(84.6-89.7)$ \\
& Corrected $^{b}$ & $93.0(91.5-94.5)$ & $97.8(97.0-98.7)$ & $91.9(90.3-93.5)$ \\
PPV (95\% Cl) & Uncorrected $^{a}$ & $16.8(10.4-23.3)$ & $22.9(16.6-29.1)$ & $15.0(21.6-8.5)$ \\
& Corrected $^{b}$ & $16.1(11.0-21.1)$ & $20.9(15.9-25.8)$ & $14.2(9.1-19.3)$ \\
NPV (95\% Cl) & Uncorrected $^{a}$ & $99.8(99.6-100.1)$ & $98.6(97.8-99.5)$ & $99.8(99.6-100)$ \\
& Corrected $^{b}$ & $99.8(99.6-100.1)$ & $99.1(98.5-99.6)$ & $99.8(99.6-100)$ \\
\hline
\end{tabular}

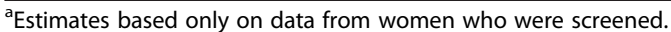

${ }^{b}$ Estimates corrected for bias due to loss of follow-up.

CIN2+: cervical intraepithelial neoplasia grade 2 or worse, hrHPV: HPV testing for high-risk types, PPV: positive predicted value, NPV: negative predicted value, 95\% Cl: 95\% Confidence Interval.

HPV detection was performed with Hybrid Capture 2 test (HC2; Qiagen, Gaithersburg, MD, USA). 
clinically relevant lesions $[12,25,26]$. In fact, studies with longer follow-up periods confirm that HPV positive women with a normal cytology harbour an increased risk in the long run of CIN2, CIN3, and invasive CC and that an increased over-detection of HPV tests can be ruled out [27]. An increased number of referral tests due to an excess of positive HPV tests in women with no disease could be an undesired effect of this strategy [26,28]. In three European RCTs about seven women had a potential false-positive screening result for each $\mathrm{CIN} 2+$ detected [26]. In our study, this ratio was 6.3 women for each CIN2+ or 14 women for each CIN3+ detected. In the ATHENA HPV trial, a screening strategy with HPV testing followed by a reflex cytology, resulted in 4.5 colposcopies per CIN2+ detected, similar to the rate of using HPV with genotyping [29]. Total number of colposcopies for CIN2+ detected in screened women is now considered a good quality indicator of overdiagnosis [30]. However, in the POBASCAM trial, the number of referrals in the HPV positive arm was considerably reduced in further screening rounds if the interval was long enough to avoid detection of acute HPV infection [25]. Efforts to minimize referrals should not only be an economical aim but also a good clinical practice aim to avoid unwanted effects of screening such as overtreatment or anxiety associated to a positive test.

European RCTs and American screening cohorts have shown that among HPV negative women, the risk for CIN2+ was very low $(0.2 \%$ and $1.2 \%$, for women without or with cytological abnormalities respectively) suggesting that safe intervals can go beyond five years if a validated HPV tests is being used [13,25,26,31,32] providing a beneficial cost-efficacy ratio [33]. In our study, $97.8 \%$ of the HPV negative women, irrespective of the cytology result, the risk for $\mathrm{CIN} 2$ was $0.2 \%$ and $0 \%$ for $\mathrm{CIN} 3+$, reassuring a safe 3-year screening interval.

In this study we have explored the strategy to protect poorly screened women by introducing a more complete screening approach. However, screen negative women were prone to a poor follow-up at 3 years as almost half of them did not return during the follow-up period consistently with that observed in other studies [14]. A behavioural study in the region identified that the large majority of poorly screened women reported poor knowledge about the relevance of CC screening [34] indicating that efforts to explain the benefits of screening should be reinforced.

Due to the differential attendance to control visits according to the screening baseline results we corrected the accuracy parameters (i.e. sensitivity, specificity) by follow-up estimates to minimize any bias [19]. We could not correct for a potential verification bias as HPVnegative women were not referred to colposcopy and biopsy. But in our study, about $7 \%$ of women with negative screening results had histological data for unknown reasons to the investigators. Unfortunately we did not have any more details on other medical reason of why these women were biopsied. However, none of these women were diagnosed with $\mathrm{CIN} 2+$. In Kulasingam et al. study, in which random biopsies were performed in all double negative women, no CIN2+ was reported [19]. Thus, the data support that if there is any identification bias the weight of it must be small.

We were concerned about the low longitudinal sensitivity of the cytology test but it is well accepted that quality of cytology depends on many factors as is extremely amenable to poor reproducibility. Although a relevant proportion of the women were menopausal, we did not find differences by age strata or by pathology laboratory but our sample size was relatively small and estimates by strata were unstable.

Strengths of this study are the performance of screening and follow-up processes in many centres across Catalonia as part of the routine $\mathrm{CC}$ screening. Co-testing with cytology and HPV allowed us not only the comparison between tests but also to speculate about different screening scenarios as testing was done blind to the other test result. Finally, the HPV testing used complied with its recognized clinical validity and reproducibility [16].

\section{Conclusions}

In a group of underscreened women participating in opportunistic screening, HPV test, as primary screening tool, was superior to cytology for CIN2+ detection with a higher longitudinal sensitivity over 3-year follow-up. Both tests had a very high NPV. Primary HPV screening followed by cytological triage could be the optimal strategy to identify CIN2+ in poor screening attenders in developed countries leading to longer and safe screen intervals.

\section{Abbreviations}

CC: Cervical cancer; CIN2+: Cervical intraepithelial lesion grade 2 or worse: HPV: HPV testing for high risk HPV types; RCTs: Randomized Controlled Trials; 95\% Cl: 95\% confidence intervals; NPV: Negative predicted value; PPV: Positive predicted value.

\section{Competing interests}

SdS received occasional travel funds to conferences/symposia/meetings by either GlaxoSmithKline, Sanofi Pasteur MSD, Merck \& Co. or Qiagen. She is consultant for Merck \& Co. FXB is member of the advisory board of GlaxoSmithKline, Merck Sharp \& Dohme, and Sanofi Pasteur MSD and of the speakers' bureau of GlaxoSmithKline. He received occasional travel fund to conferences/symposia/meetings by either GlaxoSmithKline, Sanofi Pasteur MSD, Merck \& Co. or Qiagen. BL has received travel funds to conferences/ symposia/meetings occasionally granted by either Qiagen or Roche. JM has also received occasional travel funds to conferences/symposia/meetings by Qiagen and Dako

The rest of the authors declared no conflict of interests.

\section{Authors' contributions}

RI: was responsible of the coordination for the collection and the quality of clinical data among the different pathology laboratories, had full access to all data, performed the data analysis and drafted all the versions of the 
manuscript. SdS: was the project leader and designed the study, had full access to all data, performed the data analysis and drafted all the versions of the manuscript. FXB: participated in the study design, contributed to draft the manuscript and made a critical review and proofread of the document JA, MS, NC, PP, AP, CM, MF, CG, BL, JM, AT, NB, MA: were responsible for the collection and the quality of clinical data among the different pathology laboratories and provided comments to the different drafts. All the authors: read and approved the final version of the manuscript.

\section{Acknowledgments}

We would like to thank the following persons for their collaboration in this study: Beatriz Serrano for her support in the initial construction of the database, Vanesa Rodríguez-Sales and Esther Roura for additional data analyses, Mercè Peris and Dolors Costa for their management and support when the protocol was approved, Maria Buxó, Rafael Marcos-Gragera and Jaume Galceran for providing data from the of Girona and Tarragona Cancer Registries, Marisa Mena and María Brotons for their useful comments and proof reading the article and finally Encarnación López, Rosa Forn, Rosa Solsona, Eulalia Fierro, Anna Bragulat, Gemma Falguera, Josefina Felisart, Angeles Añaños, Teodoro Sinche, Silvina Barbosa, Begoña Carral, Eulalia Fernández, Juan Carlos Riera, José Godínez, Jo Ellen Klaustermeier, Vanesa Camón, Ana Esteban, Yolanda Florencia, Isabel Català for providing follow-up information.

The development of this study has been partially supported by the Pla Director d'Oncologia of the Health Department in Catalonia and grants from the Instituto de Salud Carlos III (Spanish Government, grants RCESP C03/09, RTICESP C03/10, RTIC RD06/0020/0095, RD12/0036/0056, and CIBERESP), from the Agència de Gestió d'Ajuts Universitaris i de Recerca (Catalan Government, grants AGAUR 2005SGR 00695 and 2009SGR126), from the Lilly Foundation (Premio Fundación Lilly de Investigación Biomédica Preclínica 2012 F. Xavier Bosch) and the European Commission (7th Framework Programme PREHDICT 242061).

\section{Author details}

'Unit of Infections and Cancer; Cancer Epidemiology Research Programme, IDIBELL, Catalan Institute of Oncology (ICO), 08908 L'Hospitalet de Llobregat, Barcelona, Spain. ${ }^{2}$ Pathology Department, Consorci Hospitalari de Vic, 08500 Vic, Barcelona, Spain. ${ }^{3}$ Sexual and Reproductive Health Centre of Bages-Solsonès, 08240 Manresa, Barcelona, Spain. ${ }^{4}$ Pathology Department, Hospital General de Granollers, 08402 Granollers, Barcelona, Spain. ${ }^{5}$ Pathology Department, Hospital Universitari Joan XXIII de Tarragona, 43005 Tarragona, Spain. ${ }^{6}$ Clinical Laboratory ICS Tarragona, Molecular Biology Section, Hospital Universitari Joan XXIII de Tarragona. IISPV Rovira i Virgili University, 43005 Tarragona, Spain. ${ }^{7}$ Pathology Department, Hospital del Mar, 08003 Barcelona, Spain. ${ }^{8}$ Pathology Department, Hospital Universitari Dr. Josep Trueta de Girona. Catalan Institute of Oncology, 17007 Girona, Spain. ${ }^{9}$ Sexual and Reproductive Health centre of Mollet del Vallés 08100 Mollet del Vallès, Barcelona, Spain. ${ }^{10}$ Pathology Department, Hospital Universitari de Bellvitge, IDIBELL, Catalan Institute of Oncology d'Oncologia 08908 L'Hospitalet de Llobregat, Barcelona, Spain. ${ }^{11}$ Pathology Department, Hospital General de L'Hospitalet. 08906 L'Hospitalet de Llobregat, Barcelona, Spain. ${ }^{12} \mathrm{CIBER}$ Epidemiology and Public Health, Barcelona, Spain.

Received: 27 May 2014 Accepted: 1 August 2014

Published: 8 August 2014

\section{References}

1. Bosch FX, Lorincz A, Muñoz N, Meijer CJ, Shah KV: The causal relation between human papillomavirus and cervical cancer. J Clin Pathol 2002, 55:244-265.

2. Quinn M, Babb P, Jones J, Allen E: Effect of screening on incidence of and mortality from cancer of cervix in England: evaluation based on routinely collected statistics. BMJ 1999, 318:904-908.

3. Kyndi M, Frederiksen $K$, Krüger Kjaer S: Cervical cancer incidence in Denmark over six decades (1943-2002). Acta Obstet Gynecol Scand 2006, 85:106-111.

4. Lindqvist PG, Hellsten C, Rippe A: Screening history of women in Malmö with invasive cervical cancer. Eur J Obstet Gynecol Reprod Biol 2008, 137:77-83.
5. Spayne J, Ackerman I, Milosevic M, Seidenfeld A, Covens A, Paszat L: Invasive cervical cancer: a failure of screening. Eur J Public Health 2008, 18:162-165.

6. Igidbashian S, Maggioni A, Casadio C, Boveri S, Cristoforoni P, Sideri M: Sentinel Pap smears in 261 invasive cervical cancer patients in Italy. Vaccine 2009, 27(Suppl 1):A34-A38.

7. Zucchetto A, Franceschi S, Clagnan E, Serraino D, Zanier L, Franzo A, Friuli Venezia Giulia Cancer Registry Working Group: Screening history of women with invasive cervical cancer in north-east Italy. Eur J Obstet Gynecol Reprod Biol 2010, 152:200-204.

8. Gök M, Rozendaal L, Berkhof J, Visser O, Meijer CJ, van Kemenade FJ: Cytology history preceding cervical cancer diagnosis: a regional analysis of 286 cases. Br J Cancer 2011, 104:685-692.

9. Kirschner B, Poll S, Rygaard C, Wåhlin A, Junge J: Screening history in women with cervical cancer in a Danish population-based screening program. Gynecol Oncol 2011, 120:68-72.

10. Naucler P1, Ryd W, Törnberg S, Strand A, Wadell G, Elfgren K, Rådberg T, Strander B, Johansson B, Forslund O, Hansson BG, Rylander E, Dillner J: Human papillomavirus and Papanicolaou tests to screen for cervical cancer. N Engl J Med 2007, 357:1589-1597.

11. Anttila A, Kotaniemi-Talonen $L$, Leinonen $M$, Hakama M, Laurila $P$, Tarkkanen J, Malila N, Nieminen P: Rate of cervical cancer, severe intraepithelial neoplasia, and adenocarcinoma in situ in primary HPV DNA screening with cytology triage: randomised study within organised screening programme. BMJ 2010, 340:c1804.

12. Ronco G, Giorgi-Rossi P, Carozzi F, Confortini M, Dalla Palma P, Del Mistro A, Ghiringhello B, Girlando S, Gillio-Tos A, De Marco L, Naldoni C, Pierotti P, Rizzolo R, Schincaglia P, Zorzi M, Zappa M, Segnan N, Cuzick J: Efficacy of human papillomavirus testing for the detection of invasive cervical cancers and cervical intraepithelial neoplasia: a randomized controlled trial. Lancet Oncol 2010, 11:249-257.

13. Arbyn M, Ronco G, Anttila A, Meijer C, Poljak M, Ogilvie G, Koliopoulos G Naucler P, Sankaranarayanan R, Peto J: Evidence regarding human papillomavirus testing in secondary prevention of cervical cancer. Vaccine 2012, 30(suppl 5):F88-F99.

14. Rijkaart DC1, Berkhof J, Rozendaal L, van Kemenade FJ, Bulkmans NW Heideman DA, Kenter GG, Cuzick J, Snijders PJ, Meijer CJ: Human papillomavirus testing for the detection of high-grade cervical intraepithelial neoplasia and cancer: final results of the POBASCAM randomised controlled trial. Lancet Oncol 2012, 13:78-88.

15. Departament de Salut. Direcció General de Planificació i Avaluació: Protocol de les Activitats per al Cribratge del Càncer de Coll Uterí a l'Atenció Primària. Barcelona: Generalitat de Catalunya; 2007. http://www20.gencat.cat/docs/ cancer/MERY/HPV/protocol.pdf.

16. Ibáñez R, Félez-Sánchez M, Godínez JM, Guardià C, Caballero E, Juve R, Combalia N, Bellosillo B, Cuevas D, Moreno-Crespi J, Pons L, Autonell J, Gutierrez C, Ordi J, de Sanjosé S, Bravo IG: Interlaboratory Reproducibility and Proficiency Testing within the Human Papillomavirus Cervical Cancer Screening Program in Catalonia, Spain. J Clin Microbio/ 2014, 52:1511-1518.

17. Solomon D, Davey D, Kurman R, Moriarty A, O'Connor D, Prey M, Raab S, Sherman M, Wilbur D, Wright T Jr, Young N, Forum Group Members: Bethesda 2001 Workshop: The 2001 Bethesda System: terminology for reporting results of cervical cytology. JAMA 2002, 287:2114-2119.

18. Crum CP, Lee KR: Diagnostic gynecologic and obstetric pathology. Philadelphia: Saunders; 2005.

19. Kulasingam SL, Hughes JP, Kiviat NB, Mao C, Weiss NS, Kuypers JM, Koutsky LA: Evaluation of human papillomavirus testing in primary screening for cervical abnormalities: comparison of sensitivity, specificity, and frequency of referral. JAMA 2002, 288:1749-1757.

20. Rodríguez-Salés V, Roura E, Ibáñez R, Peris M, Bosch FX, Coma EE, de Sanjosé S: Coverage of cervical cancer screening in Catalonia, Spain (2008-2011). Gac Sanit 2013, 28:7-13.

21. Meijer CJ, Berkhof $H$, Heideman DA, Hesselink AT, Snijders PJ: Validation of high-risk HPV tests for primary cervical screening. J Clin Virol 2009, 46(Suppl 3):S1-S4

22. Luyten A, Scherbring S, Reinecke-Lüthge A, Braun BE, Pietralla M, Theiler K, Petry KU: Risk-adapted primary HPV cervical cancer screening project in Wolfsburg, Germany-experience over 3 years. J Clin Virol 2009, 46(Suppl 3):S5-S10.

23. Naucler P1, Ryd W, Törnberg S, Strand A, Wadell G, Elfgren K, Rådberg T, Strander B, Forslund O, Hansson BG, Hagmar B, Johansson B, Rylander E, 
Dillner J: Efficacy of HPV DNA testing with cytology triage and/or repeat HPV DNA testing in primary cervical cancer screening. J Natl Cancer Inst 2009, 101:88-99.

24. Castle PE, Rodríguez AC, Burk RD, Herrero R, Wacholder S, Alfaro M, Morales J, Guillen D, Sherman ME, Solomon D, Schiffman M, Proyecto Epidemiológico Guanacaste (PEG) Group: Short term persistence of human papillomavirus and risk of cervical precancer and cancer: population based cohort study. BMJ 2009, 339:b2569.

25. Bulkmans NW1, Berkhof J, Rozendaal L, van Kemenade FJ, Boeke AJ, Bulk S, Voorhorst FJ, Verheijen RH, van Groningen K, Boon ME, Ruitinga W, van Ballegooijen M, Snijders PJ, Meijer CJ: Human papillomavirus DNA testing for the detection of cervical intraepithelial neoplasia grade 3 and cancer: 5-year follow-up of a randomised controlled implementation trial. Lancet 2007, 370:1764-1772.

26. Lynge E, Rebolj M: Primary HPV screening for cervical cancer prevention: results from European trials. Nat Rev Clin Onco 2009, 12:699-706.

27. Ronco G, Dillner J, Elfström KM, Tunesi S, Snijders PJ, Arbyn M, Kitchener $H_{4}$ Segnan N, Gilham C, Giorgi-Rossi P, Berkhof J, Peto J, Meijer CJ: International HPV screening working group: Efficacy of HPV-based screening for prevention of invasive cervical cancer: follow-up of four European randomised controlled trials. Lancet 2014, 383:524-532.

28. Barken SS, Rebolj M, Andersen ES, Lynge E: Frequency of cervical intraepithelial neoplasia treatment in a well-screened population. Int J Cancer 2012, 130:2438-2444.

29. Cox JT, Castle PE, Behrens CM, Sharma A, Wright TC Jr, Cuzick J, Athena HPV Study Group: Comparison of cervical cancer screening strategies incorporating different combinations of cytology, HPV testing, and genotyping for HPV 16/18: results from the ATHENA HPV study. Am J Obstet Gynecol 2013, 208(3):184.e1-184.

30. Saslow D, Solomon D, Lawson HW, Killackey M, Kulasingam SL, Cain J, Garcia FA, Moriarty AT, Waxman AG, Wilbur DC, Wentzensen N, Downs LS Jr, Spitzer M, Moscicki AB, Franco EL, Stoler MH, Schiffman M, Castle PE, Myers ER, ACS-ASCCP-ASCP Cervical Cancer Guideline Committee: American Cancer Society, American Society for Colposcopy and Cervical Pathology, and American Society for Clinical Pathology screening guidelines for the prevention and early detection of cervical cancer. CA Cancer J Clin 2012, 62:147-172.

31. Dillner J1, Rebolj M, Birembaut P, Petry KU, Szarewski A, Munk C, de Sanjose S, Naucler P, Lloveras B, Kjaer S, Cuzick J, van Ballegooijen M, Clavel C, Iftner T, Joint European Cohort Study: Long term predictive values of cytology and human papillomavirus. BMJ 2008, 337:a1754.

32. Cuzick J, Arbyn M, Sankaranarayanan R, Tsu V, Ronco G, Mayrand MH, Dillner J, Meijer CJ: Overview of human papillomavirus-based and other novel options for cervical cancer screening in developed and developing countries. Vaccine 2008, 26(Suppl 10):K29-K41.

33. Diaz M, de Sanjose S, Ortendahl J, O'Shea M, Goldie SJ, Bosch FX, Kim JJ: Cost-effectiveness of human papillomavirus vaccination and screening in Spain. Eur J Cancer 2010, 46:2973-2985.

34. Acera A, Rodriguez A, Trapero-Bertran M, Soteras P, Sanchez N, Bonet JM Manresa JM, Hidalgo P, Toran P, Prieto G: Economic evaluation of three populational screening strategies for cervical cancer in the county of Valles Occidental: CRICERVA clinical trial. BMC Health Serv Res 2011, 11:278.

doi:10.1186/1471-2407-14-574

Cite this article as: Ibáñez et al:: Protecting the underscreened women in developed countries: the value of HPV test. BMC Cancer 2014 14:574.

\section{Submit your next manuscript to BioMed Central and take full advantage of:}

- Convenient online submission

- Thorough peer review

- No space constraints or color figure charges

- Immediate publication on acceptance

- Inclusion in PubMed, CAS, Scopus and Google Scholar

- Research which is freely available for redistribution

Submit your manuscript at www.biomedcentral.com/submit
Ciomed Central 